\title{
Tingkat Kualitas Hidup Pasien Hipertensi di Puskesmas Gunungsari Kabupaten Lombok Barat
}

\author{
Baiq Leny Nopitasaria, ${ }^{*}$, Cyntiya Rahmawatia, ${ }^{2}$, Baiq Mitasari ${ }^{a, 3}$ \\ ${ }^{a}$ Program Studi Farmasi, Fakultas Ilmu Kesehatan, Universitas Muhammadiyah Mataram, Mataram, Indonesia \\ 1baiqleny.nopitasari@gmail.com ${ }^{\text {*⿻ }}{ }^{2}$ cyntiya.apt@gmail.com; ${ }^{3}$ mitasari@gmail.com \\ korespondensi penulis
}

\section{INFO ARTIKEL ABSTRAK}

Diterima :

07-0I-202I

Disetujui :

23-0I-202I

\section{Kata kunci :}

Kualitas hidup;

Hipertensi;

SF-36;

Puskesmas.
Hipertensi merupakan kondisi peningkatan tekanan darah sistolik lebih dari $140 \mathrm{mmHg}$ dan tekanan darah diastolik lebih dari $90 \mathrm{mmHg}$. Status kesehatan yang buruk menunjukan kualitas hidup yang buruk. Penelitian ini bertujuan untuk mengetahui kualitas hidup penderita hipertensi di Puskesmas Gunungsari Kabupaten Lombok Barat. Desain penelitian ini adalah penelitian observasional dengan pendekatan cross-sectional. Responden dalam penelitian ini adalah penduduk usia 40-75 tahun. Pengambilan sampel dilakukan di Puskesmas Gunungsari Kabupaten Lombok Barat. Teknik sampling yang digunakanadalahpurposive samplingpada 69 responden yang menderita hipertensi di Puskesmas Gunungsari. Teknik pengumpulandata menggunakan kuesioner SF-36. Data hasil penelitian dianalisa secara deskriptif dengan menentukan persentase sempurna, tinggi, sedang, dan rendah. Domain fungsi fisik berada pada kategori sempurna yaitu 26 orang (37.68\%), keterbatasan fisik berada pada kategori sempurna yaitu 64 orang $(92.75 \%)$, nyeri tubuh berada pada kategori sedang yaitu 38 orang $(55.07 \%)$, kesehatan secara umum berada pada kategori sedang yaitu 46 orang (66.66\%), vitalitas/energi berada pada kategori tinggi yaitu 39 orang (56.52\%), fungsi sosial berada pada kategori tinggi yaitu 5 I orang $(73.91 \%)$, keterbatasan emosional berada pada kategori rendah yaitu 53 orang (76.81\%), kesehatan mental berada pada kategori sempurna yaitu 28 orang $(40.57 \%)$. Rata-rata nilai kualitas hidup dari 69 responden adalah 73.73 dengan kategori kualitas hidup sedang.

\section{Keywords :}

Quality of life;

Hypertension;

SF-36;

Public health center.

\section{ABSTRACT}

Hypertension is a condition of increased systolic blood pressure of more than $140 \mathrm{mmHg}$ and diastolic blood pressure of more than $90 \mathrm{mmHg}$. Poor health status indicates poor quality of life. This study aims to determine the quality of life of hypertensi on sufferers in Gunungsari Public Health Center, West Lombok Regency. The design of this study was an observational study with a cross-sectional approach. Respondents in this study were residents aged 40-75 years. Sampling was conducted at the Gunungsari Public Health Center in West Lombok Regency. The sampling technique used was purposive sampling of 69 respondents suffering from hypertension at the Gunungsari Community Health Center. Data collection technique susing the SF-36 questionnaire. The research data were analyzed descriptively by determining the percentage of perfect, high, medium, and low. Domains of physical function are in the perfect category that is 26 people $(37.68 \%)$, physical limitations are in the perfect category that is 64 people $(92.75 \%)$, body pain is in the moderate category thatis 38 people $(55.07 \%)$, general health is in the moderate category namely 46 people $(66.66 \%)$, vitality / energy are in the high category that is 39 people $(56.52 \%)$, social functions are in the high category thatis $5 \mathrm{I}$ people $(73.91 \%)$, emotional limitations are in the low category that is 53 people $(76.81 \%)$, mental health is in the perfect categoryof 28 people $(40.57 \%)$. The average quality of live value of 69 respondents was 73.73 with the category of medium quality of life.

This is an open access article under the CC-BY-SA license. 


\section{Pendahuluan}

Hipertensi atau yang dikenal dengan nama penyakit darah tinggi adalah suatu keadaan dimana terjadi peningkatan tekanan darah di atas ambang batas normal yaitu 120/80 mmHg. Menurut WHO (World Health Organization), batas tekanan darah yang dianggap normal adalah kurang dari I30/85 mmHg.Bila tekanan darah sudah lebih dari I40/90 mmHg dinyatakan hipertensi (batas tersebut untuk orang dewasa di atas I8 tahun) (Adib, 2009).

Hampir I milyar orang diseluruh dunia memiliki tekanan darah tinggi.Hipertensi adalah salah satu penyebab utama kematian dini diseluruh dunia. Di tahun 2020 sekitar I,56 miliar orang dewasa akan hidup dengan hipertensi. Hipertensi membunuh hampir 8 miliyar orang setiap tahun di dunia dan hampir I,5 juta orang setiap tahunnya di kawasan Asia Timur- Selatan. Sekitar sepertiga dari orang dewasa di Asia Timur-Selatan menderita hipertensi (WHO, 20I5).

Prevalensi hipertensi meningkat sejalan dengan perubahan gaya hidup seperti merokok, obesitas, aktivitas fisik, dan stress psikososial. Hipertensi sudah menjadi masalah kesehatan masyarakat (public health problem) dan akan menjadi masalah yang lebih besar jika ditanggulangi sejak dini. Pengendalian hipertensi, bahkan di Negara maju pun, belum memuaskan. (Depkes RI, 2007).

Berdasarkan data dari Riskesdas Litbang Depkes (2018), hipertensi di Indonesia merupakan masalah kesehatan dengan prevalensi yang tinggi yaitu sebesar 34,1\% pada tahun 2018. Prevalensi tertinggi di Kalimantan Selatan (44,I\%), diikuti Jawa Barat (39,6\%), Kalimantan Timur (39,3\%), Jawa Tengah (37,5\%), dan Kalimantan Barat (36,9\%). Prevalensi untuk Nusa Tenggara Barat didapat melalui pengukuran pada umur $\geq 18$ tahun sebesar 27,8\% (Riskesdas, 2018). Menurut Data Riset Kesehatan Dasar (Riskesdas) 2013, menunjukkan bahwa 25,8 \% penduduk Indonesia mengidap hipertensi dan mengalami kenaikan di tahun 2018 menjadi 34,I \%. Menurut Data Riskesdas tahun 20I3, menunjukkan bahwa dari $25,8 \%$ total kasus hipertensi nasional, setidaknya 5,3\% diantaranya dipegang oleh remaja berusia I5I7 tahun (laki-laki 6\% dan perempuan 4,7\%). Sedangkan di Puskesmas Gunungsari Kabupaten Lombok Barat kasus hipertensi pada tahun 2016 dalam pengukuran tekana darah penduduk $\geq 18$ tahun sebesar 1256 orang diantaraya 480 laki- laki, dan 776 perempuan. Dengan persentase sebesar $37.53 \%$. Jumlah tersebut cukup tinggi dibandingkan dengan Puskesmas lain yang berada di Kabupaten Lombok Barat.
Renwinck dan Brown mendefinisikan kualitas hidup sebagai tingkat dimana seseorang dapat menikmati segala peristiwa penting dalam kehidupannya atau sejauh mana seseorang merasa bahwa dirinya dapat menguasai atau tetap dapat mengontrol kehidupannya dalam segala kondisi yang terjadi (Angriyani, 2008).

Penelitian meta-analisis pada tahun 20II menemukan bahwa pada individu yang menderita hipertensi memiliki kualitas hidup yang lebih rendah dibandingkan dengan individu yang memiliki normotensi.Individu yang mejalani pengobatan yang rutin juga dilaporkan memiliki kualitas hidup yang lebih tinggi dibandingkan dengan individu yang bertekanan darah tinggi tidak terkontrol.Kualitas hidup yang buruk emerupakan komplikasi ditambah dengan kondisi komorbiditas hipertensi, seperti dibetes mellitus, penyakit ginjal, penyakit jantung, depresi, dan lainnya.Oleh karena itu dibutuhkan tindakan preventif dan kuratif yang tepat dalam menanggulangi masalah hipertensi.

Pengukuran kualitas hidup dapat dilakukan dengan menggunakan instrumen kualitas hidup generik yaitu 36-item Short Form and Health Survey (SF-36). SF-36 merupakan kuesioner survei yang mengukur 8 kriteria kesehatan, yaitu fungsi fisik, keterbatasan peran karena kesehatan fisik, tubuh sakit, persepsi kesehatan secara umum, vitalitas, fungsi sosial, peran keterbatasan karena masalah emosional, dan kesehatan psikis.

Penelitian ini bertujuan untuk mengetahui kualitas hidup pasien hipertensi di Puskesmas Gunungsari Kabupaten Lombok Barat.

\section{Metode}

\section{Jenis dan desain}

Penelitian ini menggunakan desain penelitian observasional dengan pendekatan cross-sectional yaitu jenis penelitian yang menekankan pada waktu pengukuran atau observasi data dalam satu kali pada satu waktu. Penelitian ini dilakukan di Puskesmas Gunungsari Kabupaten Lombok Barat.

\section{Seleksi ubjek}

Kriteria inklusi dalam penelitian ini adalah merupakan penderita hipertensi tanpa komplikasi rawat jalan di Puskesmas Gunungsari Kabupaten Lombok Barat. Pasien usia 40-75 tahun. Kriteria Ekslusi adalah penderita hipertensi rawat inap di Puskesmas Gunungsari Kabupaten Lombok Barat. Penderita hipertensi dengan komplikasi makrovaskuler seperti thrombosis otak, penyakit jantung koroner, gagal jantung kongestif, dan stroke. Pasien dengan kondisi hamil. Penderita memiliki gangguan mental. 
Perhitungan besar sampel

$$
\begin{aligned}
& \mathrm{n}=\frac{N}{\mathrm{I}+N e} \\
& \mathrm{n}=\frac{220}{\mathrm{I}+220(\mathrm{I}) \%)^{2}} \\
& \mathrm{n}=\frac{220}{\mathrm{I}+220(0.0 \mathrm{I})} \\
& \mathrm{n}=\frac{220}{\mathrm{I}+2.2} \\
& \mathrm{n}=68.75(69)
\end{aligned}
$$

pengambilan sampel (sampling) di Puskesmas dilakukan dengan cara purposive sampling.

\section{Persiapan penelitian}

Penelitian ini dilakukan setelah mendapatkan izin penelitian dari Universitas Muhammadiyah Mataram Fakultas Ilmu Kesehatan, izin penelitian dari Bappeda Kabupaten Lombok Barat dan izin penelitian dari Puskesmas Gunungsari Kabupaten Lombok Barat. Instrumen penelitian berupa kuesioner kualitas hidup SF-36, dan informed consent diajukan untuk persetujuan komisi etik.

\section{Pengumpulan data}

Data dikumpulkan pada bulan Juli 2019. Data diperoleh dengan pengisian kuesioner kualitas hidup SF-36. Data selanjutnya diinput ke dalam worksheet Word dan disiapkan untuk dianalisi.

\section{Analisis Data}

Analisis data dilakukan secara deskriptif terdapat 8 variabel dalam kuesioner SF-36. Masingmasing variabel ditentukan nilai rata-ratanya dengan cara menjumlahkan nilai dari setiap skor pertanyaan kemudian dibagi dengan jumlah pertanyaan.

Tabel 3.I Rating nilai kualitas Hidup

\begin{tabular}{cc}
\hline Kualitas & Nilai Kualitas \\
Hidup & Hidup \\
\hline Sempurna & I00 \\
Tinggi & $80-99$ \\
Sedang & $56-79$ \\
Rendah & I-55 \\
\hline
\end{tabular}

\section{Hasil dan pembahasan}

Penelitian ini dilakukan dengan metode observasional dengan pendekatan croos-sectional dengan cara pengambilan data pasien hipertensi secara langsung di Puskesmas Gunungsari Kabupaten Lombok Barat selama periode Juli 2019. Jumlah pasien yang memenuhi kriteria inklusi dan eksklusi untuk penelitian ini sebanyak 69 responden. Teknik sampling yang digunakan dalam penelitian ini adalah teknik purposive sampling. Penelitian ini menggunakan kuesioner kualitas hidup Short From $\square 36$ (SF $\square 36$ ).

Pasien dalam mengisi kuesioner dipandu peneliti yang bertujuan agar responden lebih mengerti dengan pertanyaan yang ada dalam kuesioner. Hasil penelitian kuantitatif ini disajikan dengan menampilkan karakteristik responden, bentuk tabel dan penjelasanya

\section{Karakteristik Responden}

Karakteristik responden dalam penelitian ini terdiri atas dua jenis yaitu jenis kelamin dan usia.

Tabel 4.I Distribusi Responden Berdasarkan Jenis Kelamin.

\begin{tabular}{ccc}
\hline Jenis Kelamin & Frekuensi & $\begin{array}{c}\text { Presentasi } \\
(\%)\end{array}$ \\
\hline Laki-laki & $\mathrm{I} 7$ & $24.63 \%$ \\
Perempuan & 52 & $75.36 \%$ \\
\hline Total & 69 & 100 \\
\hline
\end{tabular}

\section{Tabel 4.2 Distribusi Responden} berdasarkan Usia

\begin{tabular}{cll}
\hline $\begin{array}{l}\text { Usia } \\
\text { (Tahun) }\end{array}$ & $\begin{array}{l}\text { Frekuen } \\
\text { si }\end{array}$ & $\begin{array}{l}\text { Presentasi } \\
(\%)\end{array}$ \\
\hline $36-45$ & 7 & $10.14 \%$ \\
$46-55$ & 25 & $36.23 \%$ \\
$56-65$ & 24 & $34.78 \%$ \\
$>65$ & 13 & $18.84 \%$ \\
\hline Total & 69 & 100 \\
\hline
\end{tabular}

\section{Jenis Kelamin}

Jenis kelamin merupakan salah satu faktor yang mempengaruhi tekanan darah (Yugo Susanto, 20I5).Pada penelitian ini perempuan lebih banyak menderita hipertensi dengan persentase $75.36 \%$ sedangkan laki - laki dengan presentase $24.63 \%$. Data karakteristik jenis kelamin pasien yang mengalami hipertensi dapat dilihat pada tabel 4.I.

Jenis kelamin sangat erat kaitannya terhadap terjadinya hipertensi dimana pada wanita lebih tinggi ketika seorang wanita mengalami menopause, hal ini didukung juga oleh pendapat (Cortas, 2008), dalam Anggraini (20II), mengatakan bahwa wanita yang belum mengalami menopause dilindungi oleh hormon estrogen yang berperan dalam meningkatkan kadarHigh Density Lipoprotein (HDL). Kadar kolestrol HDL yang tinggi merupakan faktor pelindung dalam mencegah terjadinya proses aterosklerosis. Efek perlindungan estrogen dianggap sebagai penjelasan adanya 
imunitas wanita pada usia menopause. Hal ini sesuai dengan pendapat (Yuliarti, 2007), yang menyatakan bahwa ada hubungan yang signifikan antara jenis kelamin dengan kejadian hipertensi. Hal tersebut menunjukan bahwa kejadian hipertensi pada perempuan dipengaruhi oleh kadar hormone estrogen. Hormone estrogen tersebut akan menurun kadarnya ketika perempuan memasuki usia tua (menopause) sehingga perempuan menjadi lebih rentan terhadap hipertensi.

\section{Usia}

Usia responden dalam penelitian ini adalah usia 40-75 tahun. Data umur pasien yang mengalami hipertensi lebih besar pada umur 56-75 tahun dengan persentase $53.62 \%$.Semakin tua usia maka pembuluh darah akan berkurangelastisitasnya sehingga pembuluh darah cenderung menyempit akibatnya tekanan darah akan meningkat (Kosasih 2013). Data karakteristik usia pasien yang mengalami hipertensi dapat dilihat pada tabel 4.2.

Klasifikasi umur menurut Departemen Kesehatan Republik Indonesia tahun 2009. Nilai tekanan darah meningkat dengan pertambahan umur, danhipertensi sangat umum dialami oleh lansia. Populasi $\geq 55$ tahun mempunyai risiko sebesar 90\% untukmenderita hipertensi seumur hidup. Kebanyakan diagnosis hipertensi terjadi pada umur $\geq 60$ tahun (Dipiro et al, 2008).

\section{Kualitas Hidup}

Setelah diketahui skor kualitas hidup dari masing-masing responden dilakukan pengkategorian kualitas hidup sempurna, tinggi, sedang dan rendah.Skor kualitas hidup diberikan antara $0 \square$ I00.Kualitas hidup diukur dengan menjumlahkan skor 8 domain kualitas hidup sesuai dengan rumus yang sudah dibakukan.Kualitas hidup dinyatakan sempurna apabila skor akhir IOO, kualitas hidup dinyatakan tinggi apabila skor $80 \square 99$, kualitas hidup dinyatakan sedang apabila skor $56 \square 79$, dan apabila kualitas hidup dinyatakan rendah apabila skor $\mathrm{I} \square 55$.

Tabel 4.3. Hasil Kualitas Hidup Pasien Hipertensi di Puskesmas Gunugsari Kabupaten Lombok Barat berdasarkan hasil dari data yang diperoleh

\begin{tabular}{ccc}
\hline $\begin{array}{l}\text { Kualitas } \\
\text { Hidup }\end{array}$ & Frekuensi & $\begin{array}{c}\text { Presentasi } \\
(\%)\end{array}$ \\
\hline Sempurna & - & - \\
Tinggi & 16 & $23.18 \%$ \\
Sedang & 50 & $72.46 \%$ \\
Rendah & 3 & $4.34 \%$ \\
\hline Total & 69 & 100 \\
\hline
\end{tabular}

Berdasarkan hasil penelitian yang terlihat bahwa dari 69 responden; 50orang (72.46\%) diantaranya memiliki kualitas hidup yang sedang, 16 orang $(23.18 \%)$ diantaranya memiliki kualitas hidup yang tinggi dan 3 orang (4.34\%) diantaranya memiliki kualitas hidup rendah. Dari hasil tersebut dapat disimpulkan bahwa kualitas hidup dengan kategori sedang memiliki frekuensi terbanyak dengan persentase $72.46 \%$. Kualitas hidup diatas termasuk kategori yang cukup baik. Dapat disimpulkan bahwa faktor yang mempengaruhi kualitas hidup terdiri dari faktor internal dan faktor eksternal. Faktor internal antara lain kesejahteraan kesehatan tubuh, kepatuhan minum obat dan terapi farmakologi dan non farmakologis, domain fisik, domain mental, kompetensi diri dan optimism. Faktor ekternal antara lain hubugan sosial, pekerjaan dan matrial. Kualitas hidup seseorang tidak dapat didefinisikan dengan pasti oleh karena sifatnya yang sangat subjektif. Beberapa studi menyebutkan bahwa individu dengan hipertensi memiliki skor yang lebih rendah dihampir semua dimensi yang diukur berdasarkan kuesioner SF-36 dibandingkan dengan individu yang normal. Hal ini disebabkan dapat memberikan pengaruh buruk terhadap fungsi fisik, kesehatan mental, fungsi sosial, nyeri tubuh dan domain lainnya. Penelitian meta-analisis pada tahun 201 I menemukan bahwa pada individu yang menderita hipertensi memiliki kualitas hidup yang lebih rendah dibandingkan dengan individu yang memiliki normotensi.Individu yang mejalani pengobatan yang rutin juga dilaporkan memiliki kualitas hidup yang lebih tinggi dibandingkan dengan individu yang bertekanan darah tinggi tidak terkontrol. Kualitas hidup yang buruk merupakan komplikasi ditambah dengan kondisi komorbiditas hipertensi, seperti dibetes mellitus, penyakit ginjal, penyakit jantung, depresi, dan lainnya.Oleh karena itu dibutuhkan tindakan preventif dan kuratif yang tepat dalam menanggulangi masalah hipertensi terutama untuk meningkatkan kualitas hidup pasien hipertensi. 


\section{Domain Kualitas Hidup Fungsi Fisik}

Tabel 4.4. Distribusi Frekuensi Responden Berdasarkan Fungsi Fisik Penderita Hipertensi di Puskesmas Gunungsari Kabupaten Lombok Barat

\begin{tabular}{|c|c|c|}
\hline Fungsi Fisik & Frekuensi & $\begin{array}{c}\text { Presentasi } \\
\text { (\%) }\end{array}$ \\
\hline Sempurna & 26 & $37.68 \%$ \\
\hline Tinggi & 23 & $33.33 \%$ \\
\hline Sedang & I4 & $20.28 \%$ \\
\hline Rendah & 6 & $8.69 \%$ \\
\hline Total & 69 & 100 \\
\hline
\end{tabular}

Berdasarkan hasil penelitian yang terlihat bahwa dari 69 responden; 26 orang (37.68\%) diantaranya memiliki kualitas hidup yang "sempurna" ditinjau dari fungsi fisik pasien penderita hipertensi. Pada fungsi fisik pasien penderita hipertensi dari 69 responden sebagian mengalami keterbatasan dalam mengangkat benda berat, menaiki beberapa anak tangga dan berjalan sepanjang I,5 km. Hal tersebut dikarenakanpasien merasakan sakit pada bagian lutut. Pasien tidak mengalami keterbatasan dalam olah raga ringan seperti berjalan 0,5 - I km,tidak mengalami keterbatasan dalam mandi atau memakai baju sendiri. Rata- rata kualitas hidup dengan domain fungsi fisik dari 69 responden adalah 85.2 dengan kualitas hidup "tinggi”.

\section{Keterbatasan Fisik}

Tabel 4.5. Distribusi Frekuensi Responden Berdasarkan Keterbatasa Fisik Penderita Hipertensi di Puskesmas Gunungsari Kabupaten Lombok Barat $(n=69)$

\begin{tabular}{ccc}
\hline Keterbatasan Fisik & Frekuensi & $\begin{array}{c}\text { Presenta si } \\
(\%)\end{array}$ \\
\hline Sempurna & 64 & $92.75 \%$ \\
Tinggi & - & - \\
Sedang & 4 & $5.79 \%$ \\
Rendah & $\mathrm{I}$ & $1.44 \%$ \\
\hline Total & 69 & 100 \\
\hline
\end{tabular}

Berdasarkan hasil penelitian yang terlihat bahwa dari 69 responden; 64 orang (92.75\%) diantaranya memiliki kualitas hidup yang "sempurna" ditinjau dari keterbatasan fisik pasien penderita hipertensi.Pada keterbatasan fisik pasien penderita hipertensi dari 69 responden tidak mengalami masalah dengan pekerjaan atau aktifitas sehari-hari mereka seperti mencuci dan aktifitas pekerjaan yang lain. Rata-rata kualitas hidup dengan domain keterbatasan fisik dari 69 responden adalah 97.8 dengan kualitas hidup "tinggi”.

\section{Nyeri Tubuh}

Tabel 4.6. Distribusi Frekuensi Responden Berdasarkan Nyeri Tubuh Penderita Hipertensi di Puskesmas Gunungsari Kabupaten Lombok Barat

\begin{tabular}{ccc}
\multicolumn{3}{c}{$(\mathrm{n}=69)$} \\
\hline $\begin{array}{l}\text { Nyeri } \\
\text { Tubuh }\end{array}$ & Frekuensi & $\begin{array}{c}\text { Presentasi } \\
(\%)\end{array}$ \\
\hline Sempurna & $\mathrm{I}$ & $\mathrm{I} .44 \%$ \\
Tinggi & $\mathrm{I} 6$ & $23.18 \%$ \\
Sedang & 38 & $55.07 \%$ \\
Rendah & $\mathrm{I} 4$ & $20.28 \%$ \\
\hline Total & 69 & $\mathrm{I} 00$ \\
\hline
\end{tabular}

Berdasarkan hasil penelitian yang terlihat bahwa dari 69 responden; 38 orang (55.07\%) diantaranya memiliki kualitas hidup yang "sedang" ditinjau dari nyeri tubuh pasien penderita hipertensi. Hal ini dikarenakan sebagian dari pasien hipertensi mengalami nyeri pada tubuh mereka dan yang paling utama yaitu nyeri pada bagian tengkuk dan bagian kepala mengalami pusing hingga sakit yang tak tertahan. Rata-rata kualitas hidup dengan domain nyeri tubuh dari 69 responden adalah 64.4 dengan kualitas hidup "sedang".

\section{Kesehatan Secara Umum}

Tabel 4.7. Distribusi Frekuensi Responden Berdasarkan Kesehatan Secara Umum Penderita Hipertensi di Puskesmas Gunungsari Kabupaten Lombok Barat $(\mathrm{n}=69)$

\begin{tabular}{lcc}
$\begin{array}{l}\text { Kesehatan } \\
\text { Secara }\end{array}$ & Frekuensi & $\begin{array}{c}\text { Presentasi } \\
(\%)\end{array}$ \\
Umum & & - \\
\hline Sempurna & - & $2.89 \%$ \\
Tinggi & 2 & $66.66 \%$ \\
Sedang & 46 & $30.43 \%$ \\
Rendah & $2 \mathrm{I}$ & 100 \\
\hline Total & 69 &
\end{tabular}

Berdasarkan hasil penelitian yang terlihat bahwa dari 69 responden; 46 orang (66.66\%) diantaranya memiliki kualitas hidup yang "sedang" ditinjau dari kesehatan secara umum pasien penderita hipertensi. Hal ini dikarenaka kesehatan pasien yang menderita hipertensi pada 4 minggu terakhir mengatakan kondisi mereka dalam keadaan baik dan dibandingkan dengan setahun yang lalu kondisinya lebih baik. Rata-rata kualitas hidup dengan domain kesehatan secara umum dari 69 responden adalah 60.8 dengan kualitas hidup 


\section{Vitalitas}

Tabel 4.8. Distribusi Frekuensi

Responden Berdasarkan Vitalitas

Penderita Hipertensi di Puskesmas

Gunungsari Kabupaten Lombok Barat

\begin{tabular}{ccc} 
& $(\mathrm{n}=69)$ & \\
\hline Vitalitas & Frekuensi & $\begin{array}{c}\text { Presentasi } \\
(\%)\end{array}$ \\
\hline Sempurna & 8 & $\mathrm{II.59 \%}$ \\
Tinggi & 39 & $56.52 \%$ \\
Sedang & 9 & $13.04 \%$ \\
Rendah & $\mathrm{I} 3$ & $18.84 \%$ \\
\hline Total & 69 & 100 \\
\hline
\end{tabular}

Berdasarkan hasil penelitian yang terlihat bahwa dari 69 responden; 39 orang $(56.52 \%)$ diantaranya memiliki kualitas hidup yang "tinggi" ditinjau dari vitalitas/energi pasien penderita hipertensi. Hal ini dikarenakan pasien yang menderita hipertensi selalu merasa penuh semangat dan sebagian dari mereka tidak mudah merasa lelah. Rata-rata kualitas hidup dengan domain vitalitas dari 69 responden adalah 79.I dengan kualitas hidup "sedang".

\section{Fungsi Sosial}

Tabel 4.9. Distribusi Frekuensi Responden Berdasarkan Fungsi Sosial Penderita Hipertensi di Puskesmas Gunungsari Kabupaten Lombok

\begin{tabular}{lcc} 
& Barat $(\mathrm{n}=69)$ & \\
\hline Fungsi & Frekuensi & $\begin{array}{c}\text { Presentasi } \\
\text { Sosial }\end{array}$ \\
\hline Sempurna & $\mathrm{I}$ & $\mathrm{I} .44 \%$ \\
Tinggi & 9 & $13.04 \%$ \\
Sedang & $5 \mathrm{I}$ & $73.91 \%$ \\
Rendah & 8 & $\mathrm{I} 1.59 \%$ \\
\hline Total & 69 & $\mathrm{I} \% 0$ \\
\hline
\end{tabular}

Berdasarkan hasil penelitian yang terlihat bahwa dari 69 responden; 5I orang (73.9I\%) diantaranya memiliki kualitas hidup yang "sedang" ditinjau dari fungsi sosial pasien penderita hipertensi. Hal ini dikarenakan pasien penderita hipertensi tidak mengalami masalah pada kesehatan fisik atau masalah emosional yang dapat mengakibatkan aktifitas sosial mereka terganggu atau masalah emosi yang dapat mempengaruhi kegiatan sosial seperti mengunjungi teman, saudara dan lain-lain. Rata-rata kualitas hidup dengan domain fungsi sosial dari 69 responden adalah 70.8

\section{Keterbatasan Emosional}

Tabel 4.I0. Distribusi Frekuensi Responden Berdasarkan Keterbatasan Emosional Penderita Hipertensi di Puskesmas Gunungsari Kabupaten Lombok Barat $(\mathrm{n}=69)$

\begin{tabular}{ccc}
\hline $\begin{array}{l}\text { Keterbatasan } \\
\text { Emosional }\end{array}$ & Frekuen si & $\begin{array}{c}\text { Presentas i } \\
(\%)\end{array}$ \\
\hline Sempurna & 16 & $23.18 \%$ \\
Tinggi & - & - \\
Sedang & - & - \\
Rendah & 53 & $76.81 \%$ \\
\hline Total & 69 & 100 \\
\hline
\end{tabular}

Berdasarkan hasil penelitian yang terlihat bahwa dari 69 responden; 53 orang $(76.81 \%)$ diantaranya memiliki kualitas hidup yang "rendah" ditinjau dari keterbatasan emosional pasien penderita hipertensi. Hal ini dikarenakan pasien penderita hipertensi dalam 4 minggu terakhir mengalami masalah emosi seperti merasa sedih/tertekan yang mengakibatkanpasien menyelesaikan pekerjaan tidak lama dari biasanya. Rata-rata kualitas hidup dengan domain keterbatasan emosional dari 69 responden adalah 48.7 dengan kualitas hidup "rendah".

\section{Kesehatan Mental}

Tabel 4.II. Distribusi Frekuensi Responden Berdasarkan Kesehatan Mental Penderita Hipertensi di Puskesmas Gunungsari Kabupaten Lombok Barat $(\mathrm{n}=69)$

\begin{tabular}{lcc}
\hline $\begin{array}{l}\text { Kesehatan } \\
\text { Mental }\end{array}$ & Frekuensi & $\begin{array}{c}\text { Presentasi } \\
(\%)\end{array}$ \\
\hline Sempurna & 28 & $40.57 \%$ \\
Tinggi & 20 & $28.98 \%$ \\
Sedang & 9 & $13.04 \%$ \\
Rendah & 12 & $17.39 \%$ \\
\hline Total & 69 & 100 \\
\hline
\end{tabular}

Berdasarkan hasil penelitian yang terlihat bahwa dari 69 responden; 28 orang (40.57\%) diantaranya memiliki kualitas hidup yang "sempurna" ditinjau dari kesehatan mental pasien penderita hipertensi. Hal ini dikarenakan pasien penderita hipertensi tidak mengalami masalah yang sangat serius dalam kesehantan mental meeka seperti merasa gugup, tertekan, perasaan tenang, dan merasa putus asa. dan sebagian dari pasien adalah seorang yang periang. Rata-rata kualitas hidup dengan domain kesehatan mental dari 69 responden adalah 83.I dengan kualitas hidup "tinggi". 


\section{Simpulan dan Saran}

Simpulan

Berdasarkan hasil penelitian diperoleh kesimpulan bahwa tingkat kualitas hidup penderita hipertensi di Puskesmas Gunungsari Kabupaten Lombok Barat yang terlihat dari 69 responden yaitu sebanyak 50 orang dengan persentase $72.46 \%$ diantaranya memiliki kualitas hidup yang sedang. Sebanyak 16 orang dengan persentase $23.18 \%$ memiliki kualitas hidup tinggi, dan sebanyak 3 orang yang memiliki kualitas hidup rendah. Rata-rata nilai kualitas hidup dari 69 responden adalah 73.73 dengan kategori kualitas hidup sedang.

\section{Saran}

Berdasarkan penelitian yang telah dilakukan, penulis dapat mengusulkan saran untuk penelitian selanjutnya yaitu diharapkan pada masa yang akan datang peneliti selanjutnya menggunakan kuesioner lain sebagai pembanding. Untuk penelitian selanjutnya diharapkan mencari tentang hubungan atau analisis kualitas hidup pasien hipertensi.

\section{Ucapan terima kasih}

Terimaksih yang sebesar - besarnya kepada kedua orangtua, kedua dosen pembimbing, dan teman - teman seperjuangan.

\section{Daftar Pustaka}

Angriyani, D. (2008). Kualitas Hidup pada Orang dengan Penyakit Lupus Erythematotus (Odapus). Skripsi Fakultas Psikologi Universitas Airlangga. Tidak Dipublikasikan.

Brunner,\&Suddarth. (2002). Buku ajar keperawatan medical bedah (Ed. 8, Vol.I). Jakarta: EGC.

Cahyono, S. (2008). Gaya hidup dan penyakit modern. Kanisius. Jakarta

Cohen, L.D., Townsend, R.R., (2008). In the Clinic Hypertension. availablefrom: $\quad$ www.annals.org/ Intheclinic/.[Accesed 5 Maret 2010].

Cortas K, et all. Hypertension. Last update May II (2008). [cited 20I5JanI0].Availablefrom:http//:www.e medicine.com.

Corwin E. (2005). Buku saku patofisiologi. Jakarta. EGC

Depkes RI. (2006). Pedoman Penyelenggaraan dan Prosedur Rekam Medis Rumah Sakit di Indonesia. Jakarta: Depkes RI

Dewi, M. (20I4). Evaluasi pengaruh konseling farmasis terhadap kepatuhan dan hasil terapi pasien hipertensi anggota program pengelolaan penyakit kronis (PROLANIS) pada dokter keluarga di kabupaten Kendal. Tesis. Program Pascasarjana fakultas Farmasi Univesitas Gadjah Mada. Yogyakarta.

Fitrhia. (20II). Kualitas hidup penderita hipertensi di Desa Lamceu Kecamatan Kuta Baro Kabupaten Aceh Besar. Bagian Keilmuan Keperawatan Jiwadan Komutias PSIK-FIK Universitas Syiah Kuala, Banda Aceh.

JNC VII, (2003). The seventh report of the joint National Committee on Prevention, detection, evaluation, and treatment of high blood pressure. Hypertension,42:1206-52.

Laporan Nasional Riskesdas. (2018). Kementerian Kesehatan RI. Badan Penelitian dan Pengembangan Kesehatan.

Melani F. . (2016). Skripsi Evaluasi kualitas hidup responden hipertensi menggunakan instrumen SF-36 :Kajian factor usia dan tingkat penghasilan di kecamatan kalasan, sleman, DIY. Fakultas Farmasi Universitas Sanata Dharma. Yogyakarta.

Rachmawati, J.D.W. (2013). Jurnal. Pengaruh Kompetensi dan Independensi Terhadap Kualitas Audit.

Rachmawati, Y., Dyah, A.P., (20I4). Validasi Kuesioner SF-36 Versi Indonesia terhadap pasien hipertensi di Puskesmas Yogyakarta, Jurnal pharmacy, Yogyakarta, Fakultas Farmasi Universitas Ahmad Dahlan Yogyakarta,pp. I4-25.

Rahajeng E, Tuminah S. (2009). Prevalensi dan Determinannya di Indonesia. Jakarta:Pusat Penelitian Biomedis dan Farmasi Badan Penelitian Kesehatan Departemen Kesehatan RI, Jakarta.

Theodorou, Mamas et al. (201I). Quality of life measurement in patients with hypertension in Cyprus.Hellenic journal of cardiology : $\mathrm{HJC}=$ Hellenike kardiologike epitheorese, 20II; 52 (5).

WHO. (2015). World Health Statistics 2015: World Health Organization; 2015. 